\title{
COVID-19 Pandemic preparedness and response by India: Did lockdown serve its purpose? a Commentary.
}

\author{
Saurabh Rattan ${ }^{1}$, Anmol Gupta ${ }^{2}$, Gopal Ashish Sharma ${ }^{2 *}$ \\ ${ }^{1}$ District Programme Officer, CMO Office, Kangra, Himachal Pradesh, India \\ ${ }^{2}$ Department of Community Medicine, IGMC Shimla, Himachal Pradesh, India
}

\begin{abstract}
COVID-19, the novel Coronavirus, which originated in Wuhan, China, had spread rapidly across the globe in the short period of the year. Since it was a new disease, there was no medical intervention available at the outset of the pandemic. Hence, the only mode of prevention was various non-pharmacological interventions, of various levels, at various levels, that could have saved any country from the wrath of this baleful virus. Prevention and preparedness have been the critical factors in the appropriate management at the country level. Indian government acted pro-actively in the implementation of preventive strategies right from the unfolding of the events at the far south end of the country. The government of India started thermal screening at a few of the airports on the 17th of January, which is way before the first case was reported. The passengers who had travelled back into the country ever since were placed under strict surveillance, and evacuees were to be kept in quarantine for the following 14 days. At the same time, early identification of positive cases and contact tracing aptly supported by active surveillance in a few states have played a vital role in containment. As a lesson learned from other countries, the Indian government started measures like social distancing before a significant number of cases emerged in the country. On the 16th of March, govt ordered the closure of all schools in the country. GoI had shown their immaculate understanding of the benefits of nonpharmacological interventions, with the dual purpose of delaying the peak of cases and buying some time for further strengthening of the healthcare system and procurement of PPE; India started the process of lockdown on the $24^{\text {th }}$ of March. At the beginning of April month, GoI had announced significant investments of Rs.15000 crores for 'India COVID-19 Emergency Response and Health System Preparedness Package'. All the above-mentioned measures had contributed to serving the prime purpose of early, emphatic containment of SARS-CoV-2 in a country like India, inhabited by 1.3 billion people. Although the surge of cases in India seems to be high, looking just at the numbers, when we infer the same result in comparison to the no of cases would have been there without the lockdown, no action at policymakers would have overwhelmed the health services severely. Hence, the lockdown in India had served the purpose for which it was imposed, thereby had prevented major humanitarian losses on account of COVID-19.
\end{abstract}

Keywords: COVID-19, Public Health Emergency, pandemic, Epidemic, Quarantine.

Accepted on September 18, 2020

\section{Introduction}

COVID-19, the novel Coronavirus, which originated in Wuhan, China, had spread rapidly across the globe in the short period of the year. WHO notified the outbreak of Coronavirus disease as a Public Health Emergency of International Concern (PHEIC) on the $30^{\text {th }}$ of January [1], and the virus has now spread to many countries and territories. Subsequently, it was declared a pandemic by the World Health Organization on the $11^{\text {th }}$ of March 2020 [2].

The COVID-19 virus is a novel virus linked to the same family of viruses as Severe Acute Respiratory Syndrome (SARS). COVID-19 disease is caused by a new strain of coronaviruses. 'CO' stands for corona, 'VI' for virus, and 'D' for disease [3]. Earlier, this disease was referred to as '2019 novel Coronavirus' or '2019-nCoV. Symptoms can include fever, cough, and shortness of breath. Symptoms reported are similar to the flu (influenza) or the common cold, which are a lot more common than COVID-19. In more severe cases, an infection can present as pneumonia or acute onset breathlessness. More rarely, the disease can be fatal, particularly in those with comorbidities. In a few of the countries, the disease transmission amongst communities had resulted in unimaginable havoc of loss of lives due to the overwhelming of fully equipped health care facilities. This is why lab confirmation is warranted to confirm COVID-19 at the fastest pace so that mortality could be reduced emphatically throughout the pandemic. To date, the predominant mode of virus transmission reported is through direct contact with respiratory droplets of an infected person (generated through coughing and sneezing). Susceptible can also contract the infection from the contracting viruses while touching contaminated surfaces and, subsequently, inadvertent touching over their face (e.g., eyes, nose, and mouth). It is reported that the SARS-CoV2 virus may survive on surfaces for several hours, although the application of simple disinfectants can kill it [4].

Since it was a new disease, there was no medical intervention available at the outset of the pandemic. Hence, the only mode 
of prevention was various non-pharmacological interventions, of various levels, at various levels, that could have saved any country from the wrath of this baleful virus. In the past few months, the world has seen that a slight change in the way we tackle this situation could have a colossal difference in the outcome. Prevention and preparedness have been the critical factors in the appropriate management at the country level. Still, contrary to belief, many mighty and capable nations have fallen prey to the ill effect of it and had suffered immensely.

\section{Indian Scenario and Response}

Indian government acted pro-actively in the implementation of preventive strategies right from the unfolding of the events at the far south end of the country. The Indian government was instrumental in taking action swiftly right from the time when this disease was just an epidemic and yet to be declared as a pandemic. Indian govt took quick note of the events occurring in the People's Republic of China after the confirmation of the first death in Wuhan, China, on the $5^{\text {th }}$ of January. The situation was actively monitored in consultation with WHO at the highest level, Govt. of India (GoI). Although on the $12^{\text {th }}$ of January, WHO, in its latest update, mentioned that there is limited human to human transmission [5], GoI had started screening of international travelers at prominent airports. Indian govt acted exceptionally and took prompt action to extract the Indian students studying in different universities of the people's Republic of China. GoI started thermal screening at a few of the airports on the 17th of January, which is way before the first case was reported. Since then, various points of entry were put under screening, including air and seaports.

Furthermore, the passengers who had travelled back into the country ever since were placed under strict surveillance through the IDSP network "DATA." Besides, exhaustive lists were prepared for all passengers travelling from China and Hong Kong for subsequent monitoring at state levels. Moreover, the government urged passengers with a history of travelling from China for self-reporting to the nearest health facility. Later on, GoI made a formal request to China for the evacuation of Indian nationals from China on the 28th of January. Evacuees were to be kept in quarantine for the following 14 days, and appropriate quarantine centers were established. At the beginning of February, this was followed by the suspension of entry of any foreign nationals from the People's Republic of China.

By the end of February, 21 Airports, 12 major seaports, and sixty-five minor seaports along with land crossings adjoining Nepal border were under extensive surveillance. It was further subsequently stressed, with the universal screening at all entry points on the $4^{\text {th }}$ of March, 2020. At around the same time, the center had asked the state governments to explore the possible quarantine facilities across all the states. Further, the government had rolled out the cluster management plan in anticipation of the smooth management of COVID-19 in the future. On the 30th of January, GoI established a control room no +91-11-23978046 for any query to be addressed about COVID-19 [6].

Screening by thermal scanner was done at various designated airports, and by the end of January and in total, over twenty thousand patients were screened. By implementing the abovementioned measures, India delayed the explosion of the Corona
Virus outbreak in the country to the minimum extent possible. This, in turn, bought time for the govt and the health $\&$ family welfare department to prepare for the inevitable outcome. This has helped in hammering down the peak of the epidemic in a country with a large population, which could have overwhelmed the health services in India at a catastrophic pace.

National Institute of Virology, Pune, was the pioneer laboratory to test samples of SARS-CoV-2 in India at the outset of the epidemic. On the day of reporting the first case in India, the 30th of January, the government decided to augment the lab facility. Same day six more labs were started for the same which were: (1) NIV Bengaluru Unit, (2) Victoria Hospital Campus, KR Road, Fort, Bengaluru (3), AIIMS, New Delhi (4), NCDC, Delhi (5) Kasturba Hospital for infectious diseases, Mumbai (8) NIV-Kerala Unit. On $22^{\text {nd }}$ of January, ten other laboratories under the Indian Council of Medical Research's Viral Research and Diagnostics Laboratories network were also equipped to test such samples if a need arose. On the $31^{\text {st }}$ of January, ICMR - NICED, Kolkata, GMC, Secunderabad, KGMU, Lucknow, SMS, Jaipur, IGGMC, Nagpur, and KIPMR, Chennai were also recognized to function as the testing centers for Covid-19. On the $20^{\text {th }}$ of March, ICMR decided that all the notified National Labs for COVID-19 testing, including Viral Research \& Diagnostic Laboratories (VRDLs) and other Labs, spread across the country shall remain open all the seven days of a week, which included a total of 79 laboratories [7]. The government had stressed on pooling of the collective resources for which involvement of private hospitals was done to work on maximum capacity. The role of private hospitals was given due importance, and their involvement was also ensured to respond collectively to the outbreak. On the $5^{\text {th }}$ of March, a meeting was held by the GoI with the private health care providers to come together and work as an alliance for collective effort towards COVID-19 management.

Although with the characteristics owned by this virus, which had a shorter latent period than the incubation period, testing at a grand scale might not have benefitted, as the outcome of the would not have any effect on the progression of the disease [8]. Nevertheless, at the same time, early identification of positive cases and contact tracing aptly supported by active surveillance in a few states have played a vital role in containment. Bhilwara model in Rajasthan and door to door screening by health professionals in Himachal Pradesh have handed a significant role in curtailing the peak [9].

States and UT's were monitored and reviewed from time to time by the government to check for their preparedness regarding isolation wards, contingency plans, and availability of PPE and masks. On the $4^{\text {th }}$ of March, understanding the importance of non-pharmaceutical measures, the government imposed restrictions on the export of PPE, masks, and sanitizers. On the $14^{\text {th }}$ of March, govt declared the masks and sanitizers as the essential commodities under the essential commodity act to keep a check on the black marketing of the same. This act could help in making the smooth supply chain, as the states could ask the manufacturers to enhance the production of these products.

States were also directed to open control rooms, appoint a nodal officer, and popularize the control room number so that any query could be managed with a uniform response. Rapid Response 
Teams had been constituted and trained by the Health ministry in all States for managing emergencies due to high-risk pathogens by the $17^{\text {th }}$ of February. On the $11^{\text {th }}$ of March, governmentdirected all States/UTs to invoke provisions of Section 2 of the Epidemic Disease Act, 1897, so that all advisories being issued from time to time by the Ministry of Health \& Family Welfare/ State/UTs are enforceable in principle. Further, the amendment of the act was done, which provided for making acts of violence cognizable and non-bailable offenses and for compensation for injury to healthcare service personnel or for causing damage or loss to the property in which healthcare service personnel may have a direct interest concerning the epidemic [9].

Govt of India also launched a critical social security measure, an Insurance Scheme for Health Workers Fighting COVID-19, providing a cover of Rs. 50 lakh for ninety days to a total of around 22.12 lakh to public healthcare providers, including community health workers, who may have to be in direct contact and care of COVID-19 patients and who may be at risk of being impacted by this. It will also include accidental loss of life on account of contracting COVID-19. The action by the govt helped a lot, thereby providing mental satisfaction to the workers by providing a cushion of security financially and psychologically. It is established that such interventions are needed to allay their anxieties and fears while discharging their duties.

As a lesson learnt from other countries, the Indian government started measures like social distancing before a significant number of cases emerged in the country. On the $16^{\text {th }}$ of March, govt ordered the closure of all schools in the country and urged people to work from home, along with taking a vital check on the implementation of these measures of prevention. On the $20^{\text {th }}$ of March, all railway bookings were suspended, and effective from the $22^{\text {nd }}$ of March, all domestic and international flights were also grounded. This had remained suspended for the whole period of the lockdown with exceptions only to the flights under VANDE BHARAT MISSION on humanitarian grounds in a phased manner.

The government of India had shown their immaculate understanding of the benefits of non-pharmacological interventions by taking all the above-mentioned steps. Still, it was evident that the disease is going to spread in the country. So, with the dual purpose of delaying the peak of cases and buying some time for further strengthening of the healthcare system and procurement of PPE, India started the process of lockdown. Worthy Premier of the country asked for the collaboration of the people on the $22^{\text {nd }}$ of March for one-day' JANTA CURFEW' (curfew imposed on themselves). This call seemed to have a binate purpose; one to check how sincerely people adhered to it and the other to sensitize people for the upcoming long-term lockdown. Community participation at all levels ensured the success of 'Janta' curfew. Although the action of clapping or making any sound in appreciation of the health care workers on that day was debatable among many intellectuals, we, the health care workers were given a big boost of morale by that.

On the $24^{\text {th }}$ of March, the government ordered a nationwide lockdown for 21 days, which limited the movement of 130 crore Indians as a massive preventive measure. The immediate implementation of the lockdown brought forth another inevitable humanitarian crisis of migrants and its cataclysmic economic consequences of income generation. There were massive scale migrations across India, which had impacts on the surge of COVID cases as well as the rise of unemployed workers. If this extensive migration could have been preempted and planned accordingly, then the aftermath of these migrations could have been averted. This later was aptly addressed by multiple govt measures like the announcement of financial support to all affected.

At the beginning of April month, GoI had announced significant investments of Rs. 15000 crores for 'India COVID-19 Emergency Response and Health System Preparedness Package'. The funds sanctioned would be utilized for immediate COVID-19 Emergency Response (amount of Rs.7774 crores) and rest for medium-term support (1-4years) to be provided under the mission mode approach for treating Coronavirus patients and strengthening the medical infrastructure of the country. On the 19th of April Government, launched an online data pool of critical human resources for combating and containing Covid-19. A dashboard of the same was prepared. This dashboard contained state wise and district wise availability of the large pool of human resources for various activities to fight COVID-19. At the same time, the government also called for the use of iGOT online training modules mounted on an especial digital platformIntegrated Government Online Training (iGOT) portal (https:// igot.gov.in) for training and capacity building of doctors, nurses, paramedics, hygiene workers, technicians, AYUSH doctors and staff, other frontline workers and volunteers.

In the times of lockdown GoI and MoHFW had taken a note to enable the delivery of essential health services during the COVID-19 outbreak which included the provision of essential services for Reproductive and Child Health ( $\mathrm{RCH})$, immunization, communicable diseases (such as TB, leprosy and vector-borne diseases), as well as non-communicable diseases (such as cancer and dialysis). States were also advised to ensure that all health facilities, especially in the private sector, remain functional and provide critical services so that such patients who need these critical services do not face the brunt of the impact of COVID-19 on other essential health care services.

All the above-mentioned measures had contributed to serving the prime purpose of early, emphatic containment of SARS-CoV-2 in a country like India, inhabited by 1.3 billion people. The figure depicted below substantiates the utility and effectiveness of measures taken by the govt in preventing significant mortality and morbidity of the above discussed period. Although, it is still a question to ponder and beyond the scope of this commentary, how this had impacted the other spheres of human activity.

The graph in Figure 1 shows the comparisons between the cases in the real-time $v s$. the expected cases if none of the preventive measures were taken, with the effective reproductive number taken as 2 (Re). The cases have been compared on the dates of lockdowns up to the beginning of the Unlock 1, for which all aforesaid measures were implemented. Although the surge of cases in India seems to be high, looking just at the number (red line), but when we infer the same result in comparison to the no of cases would have been there without the lockdown (blue line), no action at policymakers would have overwhelmed the health services severely. Hence, the lockdown in India had served the 
Citation: Rattan S, Gupta A, Sharma GA. COVID-19 Pandemic preparedness and response by India: Did lockdown serve its purpose? a Commentary. J Public Health Policy Plann April 2020;4(4):66-69.

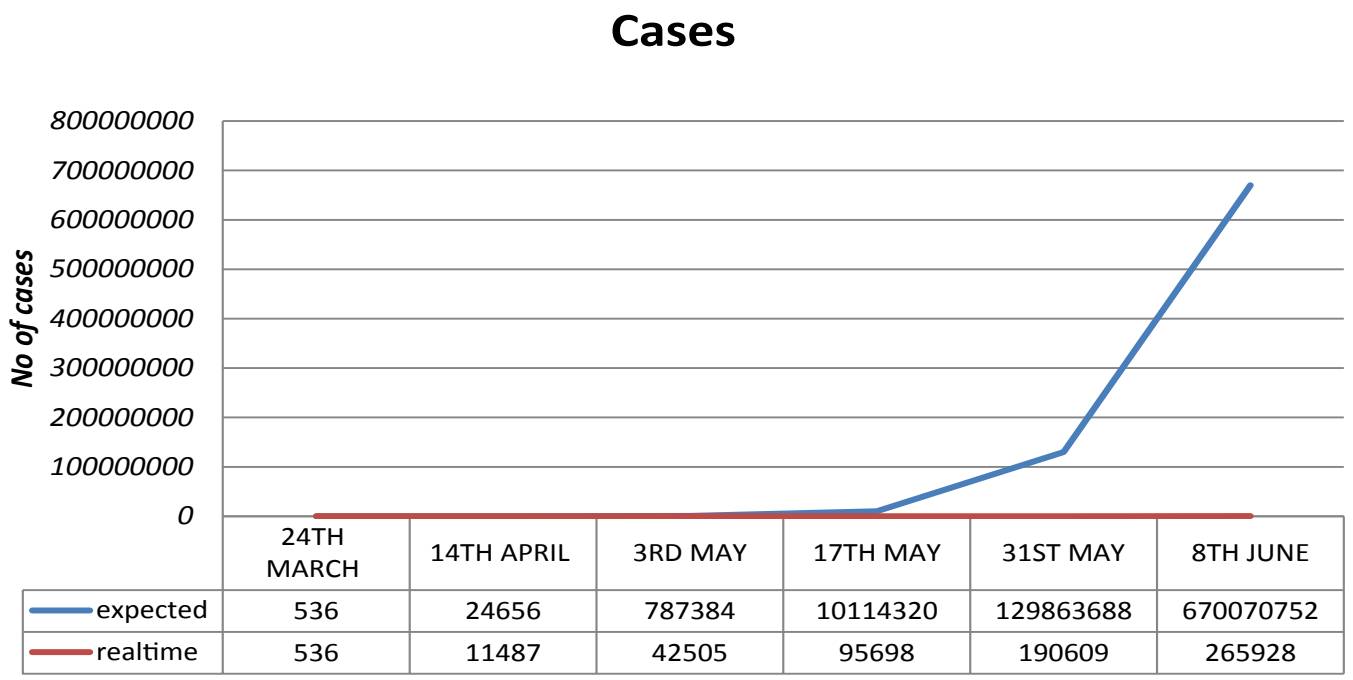

Figure 1. Comparison of cases and expected cases.

purpose for which it was imposed, thereby had prevented major humanitarian losses on account of COVID-19.

\section{Competing interests}

None declared.

\section{References}

1. WHO.COVID-19 Public Health Emergency of International Concern (PHEIC) Global research and innovation forum. Glopid R.2020;1-7.

2. WHO. General's opening remarks at the media briefing on COVID-19-11 March 2020.Global Health 2020.

3. WHO. Naming the coronavirus disease (COVID-19) and the virus that causes it.Global Health 2020.

4. WHO. Key Messages and Actions for COVID-19 Prevention and Control in Schools. Joint document UNICEF, WHO, IFRC. 2020.

5. WHO. Novel Coronavirus-China. Disease Outbreak News. 2020.
6. ICMR. SARS-CoV-2 (COVID-19) Testing Status.Covid IJMR.2020;151(2):111-260.

7. Peng Lia, Ji-Bo Fub, Ke-Feng Lia, et al. Transmission of COVID-19 in the terminal stages of the incubation period: A familial cluste. Int J Infect Dis. 2020;96: 452-3.

8. Gazette of India. The Epidemic Diseases (Amendment) Ordinance, 2020. Ministry of Law And Justice.2020.

9. Lai J, Ma S, Wang Y, et al. Factors Associated With Mental Health Outcomes Among Health Care Workers Exposed to Coronavirus Disease 2019. JAMA Open. 2020;3(3): e203976.

\section{*Correspondence to:}

Dr Gopal Ashish Sharma

Department of Community Medicine

IGMC Shimla

Himachal Pradesh

India

Tel: 09816063882

E-Mail: gashish.commed@gmail.com 